\title{
Über gutes Salz und böses Salz
}

\section{Eberhard Wolff}

PD Dr. rer. soc., Redaktor Kultur, Geschichte, Gesellschaft

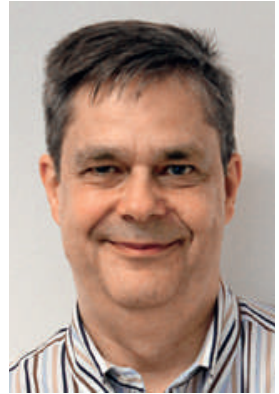

«Ach, kaufst du bitte noch Salz ein?» Der harmlose Satz führt direkt in ein neues Kampffeld des Alltags. Bereits im kleinen Quartierlädeli müssen wir uns zwischen einem jurassischen «Naturprodukt» und einer waadtländischen, natürlich reinen «Lebensquelle» entscheiden, gleichzeitig zwischen jodiert/fluoriert oder bewusst zusatzfrei.

Schon beim nächstgrösseren Detaillisten eskaliert das Herkunfts-Problem in die Dimension des klassischen Urlaubsziel-Streits: «Berge oder Meer?» Und in ersterem Fall in die Unterfrage: aus den Schweizer Bergen oder gleich aus dem Himalaya?; im zweiten Fall in: Meersalz aus dem Atlantik oder dem Mittelmeer? und dann gleich weiter: einfaches Meersalz oder handgeschöpftes «fleur de sel», extra unraffiniert, reich an Mineralien und Algen und mit gesalzenem Preis? In einem Supermarkt hinter der Grenze habe ich kürzlich fünfzig verschiedene Speisesalz-Produkte im Gestell gezählt, auch ein schwarzes aus Hawaii.

In diesem gegenwärtigen Hype sind Salzprodukte etwas durchweg Gutes. Das hat sogar ein hiesiger Telefonanbieter gemerkt. Salz ist dabei nicht nur GourmetProdukt, sondern wohltuend für den ganzen Körper, nicht zuletzt im alternativmedizinisch angehauchten Salzmarkt: «Kann in Verbindung mit frischen Zutaten eine gesunde Quelle für Nährstoffe sein», heisst es auf einer Atlantik-Meersalz-Mühle. Ganz zu schweigen von unzähligen äusserlichen Wellness-Salzpraktiken. Das ist nicht ganz neu. Vor circa 200 Jahren sangen etwa die bade- und brunnenaffinen Ärzte ein Loblied auf das Salz als Therapeutikum, wenn es oral mit dem Kurwasser oder über die Haut via Solebad vom Körper aufgenommen würde. Schon damals gab es aber Widersacher. Pharmazeuten sahen im Kochsalz nur ein Nahrungs-, allenfalls ein Abführmittel. Beide Gruppen argumentierten akademisch und jeweils nicht ganz uneigennützig, so eine historische Studie über das «schillernde Kristall» [1].

Zum «Feindbild» wurde Salz ab dem späten 19. Jahrhundert, zunächst in der gemüseliebenden Naturheilbewegung. Die u.a. salzarme oder gar salzfreie Diät des deutschen, später emigrierten Arztes Max Gerson sollte $\mathrm{ab}$ den zwanziger Jahren zunächst Migräne, dann Tuberkulose und schliesslich Krebs heilen. Der Chirurg Ferdinand Sauerbruch verhalf ihr zu zeitweise grosser Publizität. Auch Schweizer Patienten mussten sich ohne viel Heilwirkung durch die fade Kost quä- len [2]. Diäten unterschiedlicher Provenienz und Konzeption gehen bis heute davon aus, dass Salz ein medizinisches Problem darstellt.

Seit den 1920er Jahren wurde dann aber die Jodierung des Speisesalzes in der Schweiz vorangetrieben, um Jodmangelkrankheiten wie dem Kropf vorzubeugen. Seit Mitte der 1950er Jahre kam die Fluoridierung des Speisesalzes hinzu, um Karies vorzubeugen. Beides machte aus dem Kochsalz bis heute eben auch das Gegenteil eines Problems: ein Präventions- und Gesundheitsprodukt.

\section{Zum «Feindbild» wurde Salz ab dem späten}

\section{Jahrhundert.}

Seit etwa den 1970er Jahren wird das Kochsalz für einen erhöhten Blutdruck verantwortlich gemacht. Eine Annahme, über die bis heute allerdings auch heftig gestritten wird. Eine von der Schweizerischen Herzstiftung geführte Initiative kämpft - mit vorsichtigen Formulierungen - für eine Senkung des durchschnittlichen Salzkonsums, auch in diesem Blatt. Hier ist Salz nochmals etwas ganz anderes: ein Risikofaktor.

Auf dem Salzfeld findet ein Kampf um Wissensordnungen und Deutungshoheiten statt. Und solche Kämpfe gehen oft nicht ganz nüchtern, emotions- und interessenlos vor sich. Darin ähnelt das Salz anderen Grundprodukten wie dem Fett [3] oder dem traditionell hochmoralisierten Zucker. Jüngste Meldung: Am 26. November kommt mit Voll verzuckert ein launiger, in Australien gedrehter Zucker-Skandalisierungsfilm in die Kinos. Was ist also schlimmer, Fett oder Zucker, fragte Arte im Februar. Antwort: die Kombination von beidem. Wir sind nach Tissots Ratgebern, Hufelands Makrobiotik und der Lebensreform wieder einmal in einer Phase gleichsam obsessiver Selbstbeobachtung und -regulierung unserer Lebensweise angekommen, egal ob das Natriumchlorid mit Natürlichkeit, Reinheit, Wellness, Prävention oder Risiko angereichert ist - die nächste Wurst-Farce kommt bestimmt.

\section{Literaur}

1 Vogel J. Ein schillerndes Kristall. Eine Wissensgeschichte des Salzes zwischen Früher Neuzeit und Moderne. Köln u.a.: Böhlau, 2008

2 Ritzmann I. Hausordnung und Liegekur. Vom Volkssanatorium zur Spezialklinik: 100 Jahre Zürcher Höhenklinik Wald. Zürich: Chronos; 1998.

3 Colombani P. Fette Irrtümer. Ernährungsmythen entlarvt. Zürich: Orell Füssli; 2010. 